Taltra, Vol. 2, No. 1, January - June 2010, pp. 1-24 ISSN 0975-332X | https://doi.org/10.12726/tjp.3.1

\title{
Tattua
}

JOURNAL OF PHILOSOPHY

\section{THE ONE MIND MODEL OF QUANTUM REALITY: WHITEHEAD, GOD, THEORIES OF MIND, EVOLUTION, AND COSMOLOGY}

\section{Mark Germine}

"You connot shelter theology from science, or science from theology; nor can you shelter either from metaphysics, or metaphysics from either of them. There is no short cut to truth." Alfred North Whitehead (RM 79)

\section{Introduction and Exposition}

Of late we have seen a number of books that allege that science has disproved the existence of God. Often such books refer to the Darwinian theory of evolution by natural selection as the final word on the phenomenon of man. As a child psychiatrist, I recently asked a child if he believed in God. His answer was: "No, I believe in evolution." The notion that the existence of God and the general theory of evolution are mutually exclusive seems to have penetrated the very fabric of society. Darwin has, in a sense, become the prophet of a new religion, "survival of the fittest." We will argue here that evolution does not exclude the agency of God, but, in fact, requires God. 
The theory of mind is a burgeoning field, and, following a form of philosophy called eliminative materialism, it pretends to explain mind by "eliminating" or discounting subjective experience. God has been banished from science, with the justification that science must be naturalistic, while God is said to be supernatural. Scientists are increasingly identifying themselves as atheist, as are students of science, and the loy public that has been influenced by such science. Those who have not embraced the scientific dogma of atheism, and who believe in a deily, generally give no place for deity in science, and often hold two separate and mulually exclusive belief systems, a spiritual one and a scientific one.

Process theory, particularly the metaphysics of Alfred North Whitehead, gives us a natural, relational theology in which God does not simply sit idly by and watch the world go round, but is an active participant, indeed a necessary predicate, to any scientific view of reality. The explanatory power of the major scientific theories of physics, mind, and evolution have reached a limit, and much of atheistic science has become a collection of leaps of faith in the dogma of neo-classical, moterialist fundamentalism.

If you ask a child why birds have wings, the reply might be "so they can fly." This makes good sense, but assumes flying is a final cause. Final causality is forbidden by science. Birds, then, would have to have grown wings gradually in the course of evolution, without being able to fly in the early stages, and then to have discovered that they could fly. We will argue here that function of the mind also involves final causation. As stated by Whitehead (PR 277):

The mental operations have a double office. They achieve, in the immediate subject, the subjective aim of that subject as to the satisfaction to be obtained from its initial data. In this way the decision derived from the actual world, which is the efficient cause, is completed by the decision embodied in the subjective aim, which is the final cause [...] Thus the mental pole is the link whereby the creativity is endowed with the double character of final causation, and efficient causation.

The efficient cause, if we consider the mind as an actual entity, is the temporal fransition, while the final couse is the non-temporal concrescence. Whitehead further tells us that mentality is non-spatial (PR 108), or non-local, if one uses the quantum term, and, by implication, non-femporal. The process of mind can be viewed as a cycle involving the conceptual or mental pole and the physical pole. This would be consistent with Whitehead's assertions (PR 348): "For God the conceptual is prior to the physical, for the World the physical poles are prior to the conceptual poles... God is the infinite ground of all mentality." 
Mind/matter dualism, in the Cartesian sense, posits a substantial mind or "mind stuff." There is not a shred of evidence that such sfuff exists, or that the mind is substantial. Whitehead's panexperentialism makes experience primary, as it should be in science. All we know is based on experience. The existence of matter is implied by experience. We also think of matter as "stuff," but have no firm evidence beyond our senses that this is the case. Entities that are thought of substantial are really relational, and all of empirically-derived science is based on relations.

There seems to be a relation between mind and energy, which Whitehead expressed as follows. Whitehead (MT 168): "...the operation of mentality is primarily to be conceived as a diversion of the flow of energy...the energetic activity considered in physics is the emotional intensity entertained in life." Thermodynamically, energy flows down a gradient to the condition of maximum entropy, or disorder, of the mind/brain state, which is favored by the Second Law of Thermodynamics. The Second Law of Thermodynamics states that entropy increases over time, and the tendency of entropy to increase over time is often used to explain the forward arrow of time. Diversion of such flow would decrease entropy, creating negentropy or information in the Shannon-Weaver sense, and such a mechanism seems to be in operation in the functions of the brain. Information is not represented in the brain like the words in a book, and somehow magically transtormed from representotion to experience. As we will discuss later, there is a physical process of matter and energy, and a process occurring in the quantum yacuum interacting with the physical process, with the former being a kind of "blind perceptivity" and the latter being the ground for experience, exerting efficient and final causation over mental process.

Most theories of mind and consciousness assume that they are emergent phenomena, yet there is no real evidence in theory or in experimental fact to guide us as to how they emerge. The processes in the brain are qualitatively different from what we experience. The processes in the brain involve chemical interactions and electrical activity, which, on a materialistic basis, do not translate into experience. Specific functions are associated with certain regions of the brain, and neuroscience is very busy identifying these regions, but the unity and quality of experience have escaped scientific explonalion. The quest for a unifying principle of mind is called the binding problem, and it hos not been solved.

Free-will is a brute fact of our experience, yet scientific models based on classical physics are fully deterministic, leaving no room for free-will. This is an important fact, since the supposition of free-will bears directly on our autonomy, values, responsibilify, and on societal functions such as interpersonal relations and the law. Legally and medically, the inability to appreciate the nature and consequences or our acts as freely-willed agents is the hollmark of insanity. 


\section{Whiteheadean Quantum Mind Theory}

The binding problem and the problem of free will, among other things, have led many to conclude that quantum-dynamical properties are al the root of mentality. Quantum theory, unlike classical physics, is not deterministic. The reason for this indeterminacy lies in the Heisenberg Uncertainty Principle and Niels Bohr's Principle of Complementarity. Porticles like photons and electrons exisł as wave functions or fields, and properties such as the position and momentum of the particle is a field of indefinite possibilities, called quantum potentia, until a determination is made of one of these properties. The Uncertainty Principal states that, if we know the position of a particle, we cannot know its momentum, and vice versa. The same principle applies to energy and time. This relation was formalized by Bohr as the Principle of Complementarity, which he applied to the wave/particle duality of light.

Quantum potentia exist only in a probabilistic or statistical sense, and become fully actual only in a relational sense, according to the model of collapse of the wave function, which is the most widely accepted model of quantum reality. In this case the wave or wave function is a cloud of potential particles prior to collapse, at which time it becomes a single, actual particle, and the wave function is no longer present. Experimentally, determination of a single state from multiple quantum potentia involves a measuring apparatus, but the measuring apparatus, too, can be represented by a superposition of states. It is widely held that determination involves collapse of the wove function by an observer and/or consciousness. This is the model of Von Neumann, Wiger, and Stapp (Stapp, 2007). There are models that do not involve collapse, such as those of Bohm and Evereft. Bohm's theory simply replaces the wave function with a pilot wave, which is subject to the same probabilistic paramefers. His theory of the implicit order, however, has parallels with the quantum vacuum, which we will discuss later.

The model of Evereft and others has come to be known as the Many Worlds model, which implies a virtual infinily of propagoting universes corresponding to each quantum potential across these universes as they exist in all of space-time, with the observer playing no part. The Many Minds model is a species of the Many Worlds model, which to some extent is entailed by the Many Worlds interpretation, since the branching -off of separate Universes would have to reproduce universes in which our minds are present. In the formal Many Minds model of H. Dieter Zeh, our minds, or anything that can qualify as an observer, continually produce their own separate universes, each corresponding to a potential in the quantum wove function prior to observation. These non-collopse theories have been popularized under the theory of "parallel universes" or the "multiverse." 
The virtual infinity of parallel universes are all, in a sense, our universe, in that they have the same laws, the same fundamental constants, the same cosmological constant, the same particles and fields, and the same early history. These laws and properties need not be as they are in our Universe or multiverse. A small change in any of a large number of parameters would make life in our Universe impossible. It has been proposed in string theory that all of the possible parameters mentioned apply in some separate universe, and this entails another virtually infinite number of universes, all part of a "supermegaverse." Leonard Susskind (2006) estimates that there are $10^{500}$ such universes, each with its own distinctive quantum vacuum and string theory. This, according to Susskind (2006) dispels the "illusion of intelligent design." In a "super-mega-multiverse" anything that can happen does happen, science reaches a kind of causal closure, and the Anthropic Principle is fulfilled.

Consciousness-created or selected reality has lately fallen from favor as a result of the decoherence model, which holds that the potentia of the wave function are reduced by any interaction with the physical environment. For example, a green light wave entering one's eye would likely decohere into a photon of green light in the eye, and not produce a superposition of brains or minds to be collapsed by consciousness. The decoherence phenomena is what prevents us from sustaining a superposition of states for quantum computation, except under very special conditions. Decoherence is really the same thing as collapse of the wave function, but has different historical implications, and has increasingly come into favor as the term used by Many Worlds proponents. Thus, when the wave function decoheres, a single particle comes into actuality, but, in the Many Worlds models, all other potentials are actualized in separate Universes.

Collapse models that evoke consciousness or von Neumann's "abstract ego" place individual human conscious experience in a position of being the arbiter of physical reality. This idea is untenable to many. These problems, their possible solution in a theory of universal mind, and the dismissal of such a solution were described by Bohm and Hiley (1993, 23-24):

We can see several difficulties in the attempt to bring in the direct action of the mind to give an ontological interpretation of the current physical laws of the quantum theory. Thus, in the laboratory, it is hard to believe that the human mind is actually significantly affecting the results of the functioning of the instruments. [...] Moreover quantum theory is currently applied to cosmology, and it is difficult to believe that the evolution of the universe before the appearance of human beings depended fundamentally on the human mind (e.g. to make its wave function 'collapse' in an appropriate way). Of course one could avoid this difficully 
by assuming a universal mind. But if we know little about the human mind, we know a great deal less about the universal mind. (ttolics added)

Universal mind is a solution to a great dilemma in science's reigning theory of reality, which is the collapse interpretation described above. The One Mind model of quantum reality holds that there is One Mind in the Universe, and that is defined as the Mind of God. This One Mind, the Mind of God, is everywhere present through all of time and space. It makes the multiplicity of the potential one actuality, whether it be in the genesis of the Universe out of all possible universes, the selection of a particular universe out of parallel universes, or in the reduction of quantum uncertainty in measurement or collapse of the wave function. The One Mind Model of quantum reality would thus entertain a variety of current theories with equal ease. Individual minds, and the mentality of actual entities, exist in relation to the One Mind as manifestations in particular physical settings. Experimental evidence for the One Mind Model has been presented elsewhere (Germine, 2004), but is beyond the scope of this paper.

Indeterminacy becomes determinote in the concrescence (PR 23). It is God who supplies the initial subjective aim for all actualities, the appetition that moves towards satisfaction of the subjective aim in an epochal or discontinuous manner, with the non-temporal subjective aim acting teleologically as the final cause through the process of concrescence. Once this is realized through the temporal process of transition and efficient causation, the actuality in completed and passes into objective immortality. It is thus that God is "the principle of concretion," which produces an actuality from the field of potentiality. Equating the One Mind with the Mind of God, the problem of infinite possible universes is solved in accordance with Occam's principle of parsimony; all of the possibilities are brought into one, actual Universe.

Current quantum models of brain process all suffer from the same inadequacy, and that is that quantum uncertainty is, for all intents and purposes, limited to the microscopic realm. It is without question that particles, ions, other atoms, molecules, and other quantum objects exist in the brain. However, in the macroscopic realm of the brain, there is no evidence of a unifying quantum process. The brain is, fundamenfally, a classical object, leading mainstream neuroscience to adopt a classicol approach and to either ignore or deny the problems of binding, experience, and free-will. The very existence of free-will has been denied, and consciousness is widely considered to be epiphenomenal, a by-product of the brain that his no function or volitional component. Assuming evolution by natural selection, one would have to question why consciousness would develop if if serves no purpose.

The brain is a dynamical system, meaning that it is far from equilibrium at all times, and dissipates energy. Such systems are called chaotic, not in the sense that they 
are disordered, but in mathematical parlance. Chaotic systems, or systems at the "edge of chaos and order," such as the brain, exhibit the property of self-organization, or self-organizing criticality. The criticality lies in the exquisite sensitivity of the state of the system to small changes in prior physical conditions. This is the famous "butterfly effect" whereby a butterfly flapping its wings can alter future weather patterns, so as, for example, to produce a cyclone at a distant location.

As a dynamical system the brain, as per current mainstream neuroscience, would produce unpredictable states, much as the weather cannot be predicted, with all of our current fechnology. Given current conditions, the state of the system would become increasingly unpredictable with the passage of time. If one introduces quantum theory with all its uncertainties, the brain state would become even more unpredictable. This unpredictability would totally compromise the rational function of mental process, memory, and our sense of an abiding identily.

The only possible way out of this conundrum, without resorting to a mind/brain dualism, is to posit a non-temporal process which flows from the mental to the physical, thereby affecting the brain on a quantum level, with the sum of quantum events being amplified by chaotic dynamics. It is necessary that this influence be teleological, operating by final causality. Efficient causality in time would then be under the continuous influence of final causality, operating outside of time, and essentially guiding mental process. The only possible agent of such an influence would be God, as described by Whitehead previously, or what we have called Self, God within us, which we will examine shortly. Causality is not violated, since the future does not affect the past, which is already settled, and since God's knowledge of future potentialities does not entail any signals backward in time, since God in timeless or eternal.

Metaphysics, in a relativistic Universe, requires that the future be real, albeit as potential. If a plurality of possible universes exists in the future, God knows them all. The knowledge of future potentials makes the subjective aim and final causality work, and requires God as the "ground" of mentality. A panentheistic approach allows this to be the case. In God and the World we have a mutual transcendence. Nothing is supernatural. The process works within the realm of possibility or potentiality.

\section{Self, God, and Process}

The Self, Atman, as per the Hindu tradition, is the same in all of us and in all that is. The Self is God, as in the Hindu tradition Atman is Brahman. To quote from the Isa-Upanishad (Swomi and Yeats, trans., 1970, 15): "The Self is one. Unmoving, 
it moves faster than the mind... Out of Self comes the breath and the life of all things $[. .$.$] Of a certainty the man who can see all creatures in himself, knows no$ sorrow." In the Christian tradition the Self is Jesus, the Son of God. In the Buddhist tradition it has been called Universal Mind, or the Essence of Consciousness, which is known by intuition (Goddard, ed., 1970). In the Islamic Tradition there is a beautiful allegorical tale, The Conference of the Birds, composed in the twelfth century by the Persian poet Forid Ud-Altar (1961), in which all of the birds of the world meet and set out to find their king, which is a great bird, called the Simurgh. Most of them do not complete the journey to find the Simurgh, but 30 birds do. On reaching the Simurgh (131-2): "The sun of majesty sent forth his rays, and in the reflection of each other's faces these thinty birds (si-murgh) of the outer world, contemplated the face of the Simurgh of the inner world...And perceiving both of once, themselves and $\mathrm{Him}$, they realized that they and the Simurgh were one and the same being." As we shall argue later, the inner world, Whitehead's Heaven, resides in the quantum vacuum, in the outer world is the manifest physical reality that arises from the vacuum.

Ordinarily, the Self, the "Simurgh of the inner world," is unconscious for us. It is the Self that makes us actual entities, but only in the sense of the reverse polarity in which the mental or conceptual pole is ontologically prior to the physical pole. The Self can thus provide the initial subjective aim, and operate throughout the concrescence as a final cause. Such actuality is discontinuously attained in the $\mathrm{mind} / \mathrm{brain}$ state.

There is a wealth of empirical data that support this discontinuily of brain states, but in the mind it is best evidenced by cinematography. In the cinema, typically, 24 still frames per second are projected on the screen. This is quick enough that no still frames are seen, which might be the case if the brain state had a higher frequency, or even if a frame occasionally overlapped two brain states. Jason Brown, a renowned neurologist and process thinker, has developed a theory of mind called microgenesis, where each mind/brain state develops out of the self. Brown $(2008,1)$ writes: "All acts and objects develop out of a self that is laid down prior to conscious action and perception."

\section{Mind and Matter}

It is widely assumed that matter, through a complex system such as the brain, gives rise to mind. This assumption is problematic in that it makes mind, and by implication spirit, emergent from matter and not a fundamental actuality. This is the theory of emergence, which is currently the mainstream theory of mind in science. Whitehead attributes experience and subjectivity to the most fundamental actual entities, which 
become through a movement from the physical to the mental pole. Actual entities can, however, can have intellectual operations and be conscious, as Whitehead states (PR 326):

The complex of such intellectual operations is sometimes fermed the 'mind' of the actual occasion; and the actual occasion is also termed 'conscious.' But the term conveys the suggestion of independent substance. This is not meant here: $a$ better term is the 'consciousness' belonging to the actual occasion.

We encounter a problem here when we view the brain as the organ of consciousness, in that is comprised of many particles and physical fields, each of which could be considered actual entities. The brain could only be considered a society of actual occasions, or perhaps a complex or compound actual entity. A society, unlike an actual entity, is not the reason for its own becoming. However, to our knowledge, the brain is the only physical system that supporis consciousness, which Whitehead clearly attributes to an actual entity. Clearly Whitehead's epochal nature of becoming must extend beyond the quantum realm of particles. In the case of the human mind, such an extension could be envisaged as discontinuities in subjective or internal time, which for dynamical systems such as the brain could be represented by the temporality of changes in state.

The ego is also considered by Whitehead to be an actual entity, assuming that an actual occasion implies an actual entity. Whitehead addresses this in his refutation of Cartesian substantial dualism (PR 75): "For each time he pronounces 'I am, I exist,' the actual occasion, which is the ego, is different; and the 'he' which is common to the two egos is an eternal object or, olternately, the nexus of successive occasions." Adopting the former alternative, that the 'he' that is shared by the two egos is an efernal object, we note that (PR 23) "eternal objects are the same for all actual entities," implying this 'he' that is shared by the two egos can have ingression in the becoming of occasions that are totally removed from the single individual. Furthermore, Whitehead defines the eternal object as follows: (PR 44) "Any entity whose conceptual recognition does not involve a necessary reference to any definite actual entities in the temporal world is called an 'eternal object." The ego, as an eternal object, would then have to be considered to be a kind of form of mentality that is not particular to any individual.

The problem of the mind/matter duality arises as science grapples with the idea that mind arises out of matter. The importance of mind is trivialized as the physical functions of the brain are elaborated without reference to mind. There does not seem to be any empirical data explaining how consciousness arises in the brain, although, as far as we know empirically, the brain is the only system which manifests consciousness. Consciousness is seen as the end product of a process in the brain, 
through efficient causation, serving no known function. Conscious process must involve final cousation in order for consciousness in the mind/brain to be intelligible.

In his discussion of the defining characteristics of living things, Whitehead states (PR 104): "We require explanation by 'final cause.' Thus the single occasion is alive when the subjective aim which determines its process of concrescence has introduced a novelty of definiteness not to be found in the inherited data of the primary phase." In Whitehead's cosmology God supplies the subjective aim and (PR 67) "God is the organ of novelty, aiming at intensification." If we view the mind as an actual entity, as Whitehead did, we have a subjective aim, omnipresent within the brain and acting on the uncertainty of microscopic quantum processes within the brain, leading to the actuality of the mental state.

We must inquire, however, whether the process of consciousness strictly involves the movement from the physical to the mental pole, or whether movement from the mental pole to the physical pole is involved. We have fundamentally ascribed the latter movement to the agency of God. For Whitehead, God was the only actual entity for whom process goes from the mental to the physical pole. However, having God within us, which we identify as Self and the One Mind, and as God is the "infinite ground of all mentality," if would seem that conscious process may go from the mental pole to the physical pole, determining the mental state from the field of possible states. This is consistent with the "double office" of efficient and final causation at the mental pole.

\section{The Quantum Vacuum}

If God is efernal and omnipresent, and if we are to allow the agency of God into science as an explanatory hypothesis, then there must by an eternal, omnipresent field underlying physical reality. Space and time are not indefinitely divisible. There is a minimum space and a minimum time, called the Planck space and time, beneath which the space-time continuum doesn't seem to exist $\left(t^{\prime}\right.$ Hooft, 2005). The fundamental reality beneath the scale of the Planck space is called the quantum vacuum. Particles are continuously arising out of the vacuum and going back into the vacuum. In fact, it now appears that all of matter, and in fact all of reality, may be continually arising and re-emerging into the quantum vacuum, and many theorists now argue that space-time itself arises arise out of the vacuum.

The phenomenon of decoherence may also arise out of vacuum interactions. It has been proposed that violalion of the Second law of Thermodynamics, which produces negentropy or information, involves negalive energy arising out of the vacuum. It 
has also been proposed that whether or not the increase in entropy dictoted by the Second Law leads to the forward arrow of time depends on the time reversibility or irreversibility of interactions with the vacuum.

The approximate dimension of the Planck length is $10^{33} \mathrm{~cm}$, twenty orders of magnitude smaller than the proton and neutron, defining a Planck area and a Planck space. The Planck time is about $10^{-42}$ seconds, the time it takes light to cross the Planck length (Susskind, 2008). The Planck mass seems to be incredibly large when we consider the size of the Planck area. It is roughly the mass of ten million bacteria, and, if converted to energy, would be obout the same as a full tank of gasoline. It would take a particle accelerator roughly the size of the galaxy to accelerate a particle to such energy. The quantum motion arising out of the vacuum, caused by the Uncertainty Principle, keeps the electron from folling into the nucleus, making the atom 100,000 times larger than the nucleus (Susskind, 2008).

According to Nobel Prize laureate Gerard t'Hooft $(2005,2)$, "[...] particles and their properties are not, or are not entirely, real in the onfological sense. The only realities in this theory are the things that happen at the Planck scale. The things we call particles are chaotic oscillations of these Planckian quantities." These quantities, the energies that arise from the quantum vacuum, have been theorized to give rise to the quantum behaviors and uncertainties seen at a higher level of description $\left(\mathrm{I}^{\prime}\right.$ Hooff, 2005). There is established experimental proof for the existence of the quantum vacuum and some of its propenties (Schweber, 1994; Laszlo, 2004), alfhough there is much about its nature that is theoretical or unknown.

There are many theories of what might be inside the quantum vacuum, including quantum space-time foam and wormholes which allow instantaneous transport to distant regions of space-time. The Planck space-time units seem to be indefinitely entangled, or interconnected, throughout the space-time structure of the Universe, providing a kind of instantaneous connection of all of space-time. This is rather like Whitehead's concept of the extensive continuum as a field of potentiality underlying all of space and all of time - past, present, and future. To quote Whitehead (PR 72):

The extensive continuum is that general relational element in experience whereby the actual entities experienced, and that unit experience itself, are united in the solidarity of one common world. The actual entities alomize it, and thereby make real what was antecedently merely potential. The atomization of the extensive continuum is also its temporalization; that is to say, the becoming of actuality into what in itself is merely potential. 
The solidarity or the Universe proposed by Whitehead can only be met through the medium of the instantaneous connectivity of the quantum vacuum. As Whitehead (PR 57) stated: "The creative action is the universe always becoming one in a particular unity of self-experience, and thereby adding to the multiplicity which is the universe as many." This "unity of seff-experience" is a function of what we call the One Mind.

The quantum vacuum gives us a logical structure for what Whitehead called internal relations. The vacuum is the only "inside" that an ontology consistent with modern physics has. Whitehead conceived of actual entities or occasions as having a temporal duration and a region of space, which cannot be said to formally exist within the vacuum. However, if we consider experience to be the fundamental reality, then the vacuum would be an enormous, virtually infinite, field of experience, apparently outside of space-time, yet encompassing all of space-time. Such experience entails an actual entity, and since God is the only non-temporal, nonspatial, Universal actual entity, God must be that actual entity, in Whitehead's cosmology. This is not to limit God, but only to express the inferaction of God and the World, which is the proper subject of science when the hypothesis of God is entertained.

Geoffrey Chew (2004), the renowned quantum physicist, has recognized the importance of the vacuum both for our theory of reality and for Whitehead's metaphysics. He describes what he calls "pre-events," arising out of the vacuum, providing the "impulse" for the actual occasion. Chew writes that (87): "[ ...] objects (i. e. matter) correspond to regular localized patterns of large numbers of occasions [...] The identity of an object, such as an electron or the reader of this book, resides in the detailed structure of its repeating pre-event pattern." Chew (87) describes the history of the Universe as a "single choin of Whiteheadean preevents." He also describes immaterial pre-events, that are (87) "patterns associable with a 'vacuum' that provides geometry for space-time at suitably large scales." A pre-event pattern, he writes (88), would be a record of observation or memory in an enduring actual occasion. The timing of pre-events, he writes, is on the scale of the Planck time, which would mean that such events are occurring at a frequency of about $10^{42}$ times per second.

The relationship between the vacuum and physical reality has led quantum physicist Manfred Requardt (2009) to challenge the application of the quantum laws down to the level of the quantum vacuum. He states (2) "We rather view the holographic hypothesis as a means to understand how quantum theory and gravitation do emerge as derived and secondary theories from a more fundamental theory living on a more microscopic scale. The central role in this enterprise is played by an 
analysis of the microscopic structure of the quantum vocuum which leads to the key concept of wormhole spaces." According to Requardt (2009), matter and energy reflect and interact with the structure of the quantum vacuum. He proposes that this structure contains nodes of information transfer that can be arranged in various ways such as to maintain a local structure, while at the same time bringing about a non-locality which fundamentally provides instantaneous transmission of information on a Universal scale at the most basic level of reality. In order to describe the quantum vacuum, he proposes a new kind of dimension, the holographic dimension, where information exists in a universally holographic and interconnected form, placing each unit of space-time in fundamental contact in a Universal synthesis of information. This is very much like the manner in which a hologram contains the entirety of a visual image at every point. It is very similar to the holomovement of David Bohm, with the holographic implicate order, here the holographic vacuum, giving rise to the explicate order, the visible space-time reality of energy and matter.

Materialism has a precarious foundation on the ground of reality, but it can say nothing about what is beneath that ground, in the sub-Planckian realm of the quantum vacuum. Viewed from this metric, there seem to be two worlds, and this is consistent through much of Whitehead's work (RM 103): "A mental occasion is an ultimate fact in the spiritual world, just as a physical occasion of blind perceptivity is an ultimate fact in the physical world. There is an essential reference from one world to the other." In order for mentality to exist in a "spiritual world," the "spiritual world" must pervade and underlie the substance of the brain, while exerting causal influence including final causation over the evolving mental state. This role seems to be uniquely fulfilled by process in the quantum vacuum.

Indian mathematician and physicist Sisir Roy (2009) posits a generalized time within the vacuum, which is different than physical time, but by "limitation" gives rise to physical time. In generalized time, according to Roy, there is no "before" or "after." There are certain similarities here between what has been termed in Whiteheadean thought as genetic and physical time. The idea that temporal extension becomes is summarized by Whitehead in the following passage (PR 69):

The conclusion is that in every act of becoming there is the becoming of something with temporal extension; but the act itself is not extensive, in the sense that it is divisible into earlier and later acts of becoming which correspond to the extensive divisibility of what has become.

Roy makes reference to the quantum vacuum as the "veiled reality" of d'Espagnat, and points out that, in Indian Philosophy, "Maya," which is translated as illusion, 
has a meaning related to "measure," and hence to limitation, which he identifies with the genesis of physical time. In his philosophical analysis he describes the vacuum as a noumenal realm of limitless subjectivity, which gives rise to the phenomenal realm of limitless objectivity (Roy, 2009).

What emerges from these descriptions of the quantum vacuum is a relational continuum that is fundamentally timeless and spaceless giving rise to phenomenal reality. The vacuum may be viewed as a medium for prehensions extending from the scale of the particle to that of the Universe. Phenomenal reality would then arise through the transition to the fully aftained actuality as the limits of the Planck dimensions are exceeded, at which point the entity enters the mode of presentational immediacy. The polarity of the actual entily develops with a physical pole in the world of matter and energy that emerges from the vacuum into temporality and the non-temporal mental pole that remains in the realm of the vacuum.

In the Universe as we know it, the highest expression of the Mind of God is in humanity. However, the Mind of God is so far above the Mind of man as to be inscrutable, and the upward evolution of the mental and spiritual nature of man will continue to limits we can only imagine. God's creation of man is ongoing, and it is a part of God's satisfaction that we evolve toward divinity. Teilhard spoke of this process as "Christogenesis." This process will necessarily involve the emergence of Self into consciousness and the transcendence of ego-consciousness, and lead us as a species to the New Jerusalem.

\section{The Ego and the Self}

That the mental pole would be organized in the quantum vacuum on a Universal basis would seem to follow from the spacelessness and timelessness of the vacuum. Harmony, not competition, is the predominant evolutionary force which God actualizes in nature (RM 156). The Self arises as a reality in the brain, fundamentally, as a place for God to realize that harmony. This Self, together with the evolving brain, has its highest purpose in unity with God. The unity of Self/God is the same as the Atman/Brahman unity.

We are in this Universe for a reason, to live in harmony. We are a species very early in our evolution, and our future is uncertain, but there is no way to stop this progressive harmonization, which is a final cause in the Mind of God, which we call the One Mind. As the supreme actual entity, the consequent nature of God is the reason for His own becoming, and that becoming has a unitary relationship with the becoming of the World or Universe. The One Mind Model of quantum 
reality essentially holds that the One Mind manifests itself in nature as a single, actual Universe evolving over time over a particular trajectory. The Universe, as per Charles Hartshorne, is the body of God. Actual entities then would all belong to this Universal organism.

The ordinary use of the ego is reflected in Webster's dictionary, which lists the first definition os "the self, especially as contrasted with another self in the world." Egotism is defined as "on exaggerated sense of self-importance." There is also a psychological concept of the ego, which shares some features of the ordinary definition, but differs in some ways, as we will discuss shortly.

Albent Einstein held that our separateness from the Universe and others, which we ascribe to the arrogated ego, is a delusion, as in the following famous quotation:

A human being is a part of the whole, called by us, "Universe," a part limited in time and space. He experiences himself, his thoughts and feelings as something separated from the rest - a kind of optical delusion of his consciousness. This delusion is a kind of prison for us, restricting us to our personal desires and to affection for a few persons nearest to us.

The ego, as defined psychologically, is a concept derived from Sigmund Freud's structural model of the mind as comprised of id, ego, and superego. The ego, as so defined, provides our orientation to reality, including the rational function of the intellect and our identity. It mediates between the id, which expresses the "drives" of the "pleasure principle," and the superego, which tends to limit the satisfaction of the drives when they are in conflict with values and conscience. The mature ego channels and satisfies the drives in a way that can be beneficial to the individual. Freud saw the ego as the gateway to consciousness, partly conscious and partly unconscious. By allowing contents of the unconscious to reach consciousness, the Freudian ego seves as a filter, both for the organization of unconscious processes and filtering of irrelevant or unpleasant contents.

In the work of Carl Jung, the Self is an archetype of the collective unconscious. Jung's concept of archetypes is similar to Whitehead's concept of eternal objects. Self, Jung believed, is the center of the psyche. Ego has its center in Self, and it is the reunification of Self and ego that is the goal of individuation in the latter part of life.

Erich Neumann (1954) followed Jung but also diverged from Jung on some key points. In the child, Neumann holds (45) "the conscious ego is still incompletely 
separated from the unconscious self...these elements belong to the eternality of the Divine Child." Ordinarily, this separation is completed in adolescence, with development paralleling human hisłory (114):

Through the heroic act of world creation and division or opposites, the ego steps forth from the magic circle of the uroboros [unconscious self] and finds itself in a state of loneliness and discord. With the emergence of the fully fledged ego, the paradisal situation is abolished; the infantile condition, in which life was regulated by something ampler and more embracing, is at its end, and with it that natural dependence on that ample embrace.

Erich Edinger (1972) followed in the tradition of Jung and Neumann, and picked up Neumann's idea of the ego-Self axis. Inflation of the ego, which he equates with $\sin$, is caused by ego identification with the Self, causing the loss of support of the Self, or disruption of the ego-Self axis. We have termed this apotheosis of the ego. This condition can only be remedied when the Self is restored to its lost honor through repentance or contrition. This payment for the ego's $\sin$ is a necessary condition for grace, and necessitates the Self's self sacrifice. It is than that the healing power of grace can occur from the Self to the ego.

There are some clear parallels between the Judeo-Christian tradition and the history and development the ego and Self, which also bear on our contention that God is a necessary predicate of mentality and consciousness. Neumann said that, with the "development of the fully fledged ego" the paradisal situation is lost. There are two Biblical stories that seem to give an account of the Fall. The first is the expulsion of Adam and Eve from the Garden of Eden. By eating of the tree of the knowledge of good and evil, Adam, or ego, was making himself equal to God, or Self. Parallel to this is the story of the fall of Lucifer. Lucifer was an angel of God in Heaven or Paradise, who committed the sin of thinking himself equal to God, and, because of his sin, was cast down into the earth. So, Lucifer can be seen as the equivalent of the inflated or arrogated ego that sees itself equal to Self.

The Fall is mythological as well as developmental and historical. Its meaning derives from the developmental and historical separation of ego and Self, brought about, not by the development of the ego, but by its separation and illusion of being the "god of its own universe." This process is a kind of solipsism, and it is therefore not surprising that a similar solipsism has found its way into our theories of mind and reality. 


\section{Solipsistic Minds}

Our current, mainstream views of the mind are, in a sense, solipsistic. The word solipsism is derived from the Latin solus, alone, and ipse, self. In the mainstream scientific picture, we are very much alone in our own selves. It is widely held that our interactions with others are based solely on our own "theory of mind." So love, for example, is not a feeling that we experience towards some individual or individuals, but is limited to our brain's construction of that individual in cognition, behavior, and memory. Despite all intuitions to the contrary, there can be no true emotional reciprocity befween people, only interactions of representations in each separate mind. While not completing the general definition of solipsism as denial of the existence of anything outside ourselves, this fulfills a part of the definition in that, inside ourselves, we are very much alone, according to scientific materialism.

As we had discussed before, quantum decoherence, along with the classical behavior of macro-objects, prevents us from formulating a quantum theory of the mind/ brain without final causality. This entails knowing the possibilities of the future and positing one possibility as a subjective aim, presiding over the concrescence throughout the process of transition through efficient causation. This requires an omnipresent, omniscient God. Thus we posit panentheism as a fundamental reality, and in so doing avoid the solipsism of separate minds.

We may propose that God is solipsistic in the sense that He knows all that it is possible to know. At the same time, as Whitehead stated, the World transcends God as much as God transcends the World. If we read World as One Universe, and God as the locus of One Mind, we can see that the consequent nature of God continues to grow and evolve with the Universe, requiring in a sense the process of transition that belongs to the Universe. Decoherence is a result of reactions with the environment, but the Universe has no environment. It is the Universe alone that, physically, can be considered self-referential in the quantum sense.

We are proposing here that consciousness is a two-way process. The Self - God within us - is the final cause from the outset of the evolution of the brain state, with a degree of freedom resting on the efficient causation inherent in the ego-structure of the mind/brain. We view the brain state as having a duration for efficient causation, which belongs to space-fime. The brain state, under efficient causation, is on the edge of chaos, and exhibits what is called self-organizing criticality. This critical dependence on very small changes allows the subjective aim, concrescence, and final causation to operate outside of space-time, in the quantum vacuum, on the sum total of all of the microscopic quantum uncertainty in the brain over that duration of efficient causation of the brain state. However, that uncertainty cannot 
be used to actualize a state that is not within the realm of potential states, which uniquely belong to the individual organism, and which are dependent of the structure and function of the mind/brain.

There is a kind of subtle solipsism in the notion that the individual mind or consciousness collapses the wave function, bringing about definite actualities out of potentialities. These models assume that the individual mind has a separate interaction with the brain (Stapp, 2007), and are thus dualistic. They are solipsistic in the sense that they posit no interdependence or need for an interaction of experience or consciousness outside of the individual brain. The Many Worlds/ Many Minds models take a further turn towards solipsism by having our individual minds take on the function of maker of our own apparently private universes.

\section{Evolution}

The evolution of life on earth is a scientific fact, which would be futile to argue from any perspective. Charles Darwin developed the theory of evolution by natural selection. In doing so he made a major assumption, which we challenge here, and that is that there is no final causation in evolution.

Natural selection is like a ticket to board the train. You need a ticket to get on the train, and the ticket determines where you must get off. The ticket does not make the train, drive the train, power the train, determine what path the train will take, or create you as a passenger. Lord Kelvin, in the nineteenth century, argued against the Darwinian theory of evolution by natural selection on the basis of the new science of thermodynamics. Brooks and Wiley (1986) showed that the laws of thermodynamics, particularly those that cover negentropy, or order, seem to govern evolutionary diversity. They concluded (195): "Rather than assuming that environmental selection is the 'only directive force' in evolution, we do not think it is direction giving at all." More recently Stuart Kaufmann (2000) described selforganizing patterns and processes that seem to govern much of evolution. This self-organizing criticality makes evolutionary and ecological systems subject to final causality in the same way as the mind/brain system is.

It seems that, in the course of evolution, features arise that are later co-opted for other purposes, or from features that seem to serve no purpose at all. These fealures are called preadaptations. This term was later abandoned for the alternative, exaptation, to avoid the implication of final causality, although the term preadaptation is still sometimes used. The ancestors of birds, for example, are said to have developed feathers for thermal regulation, which were lately critical to flight. The wings of birds are said to have developed gradually, again as a means of thermal regulation. 
A well-known example of an exaptation is the rapid evolutionary growth of the human brain, leaving spaces or spandrels, which were thought to have been later co-opted for language, art, commerce, war, and other functions (Buss ef al., 1998). It should be noted that the large cranium of humans had a negative survival value. The pelvic orifice in the female had to be widened substantially to give birth, leading to deoth of the infant and/or mother in those that did not have a wide pelvic orifice. Notwithstanding, infant and maternal mortality in childbirth, as a result of delivery of a large cranium, would have remained high. In order for the enlarged cranium to be delivered through the pelvis, infants would have to be delivered at an early stage of development, making them unable to survive for a substantial period of time without protection and care, further increasing infant mortality. These changes would hove to have co-evolved with the increasing size of the human brain. In terms of natural selection, there would have had to have been a clear survival and reproductive benefit of the enlarged brain, and brain size would have had to have been an adaptation offsetting these maladaptive fealures. This adaptive value would also have been sufficient to warrant co-evolution of other features. However, the rapid growth of the human brain was recognized as a preadaptation by Steven J. Gould (Buss et al., 1998), arguably the greatest evolutionary scientist of the twentieth century.

The eye is another complex organ that had to have evolved in stages. Referring to work of philosopher David Drew, Stuart Kauffman, whose earlier and brilliant work on self-organizing systems and evolution we have briefly discussed, noted with approval that Drew had spoke of the evolution of (Kauffman, 2009, 5) "the eye, or even a red light sensitive cell in the progeny of an organism with no light sensitivity, as a 'blind teleology." It is interesting that Kauffman, referring to a 2009 paper of Steven Hawking, the famous physicist, entitled "Godel and the End of Physics," states that (Kauffman, 2009, 2) "no finite set of laws may suffice to describe by entailment the evolution of the physical universe." Kauffman describes the preadaptation as fundamental to evolution, and goes on to say that (3) "the evolution of the biosphere by Danwinian exaption, or 'preadaptations,' is not describable by sufficient natural law." He argues that the opportunity for adaptation is a "blind final cause," which is the missing "why" of Darwinian evolutionary theory. He argues for a partially lowless and creative universe, such the evolution of the biosphere and of species is inherently unpredictable.

If we accept the notion that evolution occurs through preadaptations, which ore unpredictable in both origin and outcomes, but are somehow propagated in the biosphere by blind teleology or blind final cause, not describable by natural law, we must inquire as to how the blind teleology is referred to some future actuality. If the phenomenon is not referable to some future actuality, or possibility of actuality, 
how can it possibly be called a final cause? If there is connection between the phenomenon and some future actuality, in what sense is it blind? God produces final causes from the realm of the possible future, and such final causality would help explain the difficulties which we have in explanation of preadaptation and other evolutionary problems.

For Whitehead the "microscopic process" of the indeterminate reality of the future becoming the deferminate actuality of the current occasion is teleological (PR 214). Later in the same passage Whitehead states that the actual entity (PR 215) "repeats in microcosm what the universe is in macrocosm," perhaps suggesting a wider purview of the teleology of the actual occasion. The process goes in two directions, from the microscopic to the macroscopic to the microscopic, from God to the World and from the World to God. Actualities in the World emerge through self causation only in the context of this intercourse between God and the World.

The Cambrian explosion occurred around 520 million years ago and marks the first appearance of dozens of animal phyla, including nematodes, annelids, mollusks, arthropods, echinoderms, and chordates. The chordate phylum includes all animals with spinal chords, so the Cambrian explosion seems to mark our distant ancestry. The rapid appearance of many of the major current phyla of animals was a challenge to Dorwin and the theory of natural selection, and he acknowledged this in the Origin of the Species, finding it a serious and inexplicable problem and a valid argument against his theory of evolution by notural selection. There have been many plausible explanations for the phenomenon, but no clear scientific evidence. Simon Morris $(2003,1)$ opined that "the sudden emergence of a whole series of different body plans from an effectively identical worm invokes an almosi homunculuslike effect, whereby each phylum has a latent form somehow concealed within the primitive worm." Moreover, in the Cambrian explosion, evolution appeared to occur from the "top down," with higher categories of animals, or taxa, arising first, and lower taxa appearing later (Kauffman, 1993).

One explanation for the Cambrian explosion is that ecological niches were unoccupied, leaving the opportunify for new types of animals to evolve (Kauffman, 1993). Thus evolution may involve the absence of natural selection, since these organisms would have had to rapidly evolve without selection pressure. Be that as it may, the latent potential for the evolution of higher taxa and the filling in of taxa from the top down speak of final causation.

Genetics is the foundation for evolution, so we might expect to find genetic mutations that confer fitness to be selected in the course of evolution. Other mutations that don't affect fitness are called neutral. In a 1968 article in Nature on the rate of evolution, by Motoo Kimura, it was determined that, in the evolution of mammals, 
genetic mutations by nucleotide substifution occur, on average in the population, every two years (625). This is in contrast to the standard-rate evolution estimate of substitution in a population or around one every 300 generations. Kimura (1968) described these frequent mutations as neutral, and estimated the rate of neutral mutations in mammals to average about four per gamete (sperm or egg) (625). The mutant genes seem to be fixed or established in the population at about the same rate that they occur (625). These data make it clear that genetic mutations in populations, are not, for the most part, those that are fixed by natural selection, and imply that the rate of evolution is not substantially governed by natural selection.

Neutral mutations occur at such a regular rate that they can be used to estimate the date of common ancestry of groups or populations of organism. It is of interest that we humans, it would appear, nearly went extinct, in that the genetics can be traced back to ancestry from a single human individual, at two times in geologically recent history. The $Y$ chromosome is passed down only through the male line and the mitochondrial DNA strictly through the female line. There is a time-dependent phenomenon of genetic alteration that makes the DNA more variable as measured in populations over time, enabling geneticists to determine the most recent common ancestor. The mitochondrial "Eve" lived around 200,000 years ago, most likely in East Africa, and is thought to be the ancestor of all current humans. The $Y$ chromosome Adam, also thought to be ancestor of all current humans, lived about 60,000 years ago. This means that if either of these two individuals hadn't lived or hadn't reproduced, chances are we wouldn't be here. The fact of our existence would then mean that either we are very lucky, and/or that our being here is a final cause of our survival.

Alternatively, had our species not had these "close calls" the genome would be a lot more diverse than it currently is, and more than one human species may have developed. Lack of genetic diversity adversely impacts capacity to adapt and survive, in Danwinian terms. As it is, we are a single subspecies, Homo Sapiens, genetically divided only by race. If we were more diverse, what would be the consequences for a future world culture? What will be the consequences for our future, based on our extremely narrow genome?

Regarding these questions, one can only guess. Our lack of genefic diversity supports the principle that we are all equal. No one race is inherently inferior to another. This fact should allow us more readily to form a cohesive world culture. Moreover, the racial genetic homogeneity of humans is increasing, particularly in countries like the United States. On the other hand, our lack of genetic diversity may cause us to be more susceptible to certain diseases. We are the only animal that can develop AIDS, although the chimpanzee, thought to be our closest living relative, 
can be infecled by the HIV virus. The HIV virus does not have a capsule, and thus dies very quickly when exposed to air. It therefore cannot be transmitted orally or by becoming airborne. If it had a capsule, it would spread like the influenza and the common cold viruses. Our cosmopolitan world insures the geographic transmission of disease pathogens such as viruses and bacteria.

\section{Conclusion}

The future is potential, known as such only to God. Humankind is faced with challenges as well as opportunities. We manifest in groups as we manifest as individuals. Some 200 years ago the scientist Pierre Simon Laplace famously said regarding God that there was no need for such a hypothesis. Scientists today have much the same attifude. God must be causal if $\mathrm{He}$ is to be relevant to science. God is necessary at the scientific level of description as the agent of final causality. Both God and final causality are strictly forbidden by orthodox science. We have argued here that there now is a need for God in our hypotheses, and that, defining God and His functions on a Whiteheadean basis, the hypothesis of God has substantial explanatory power.

We argued here that the mind must be quanitum, which has been argued by many others. Quantum mechanisms for mind and consciousness are deficient in that the brain, although supporting a wealth of quantum processes on the level of the particle, and to a less degree on the atomic and molecular levels, cannot support the necessary level of quantum coherence, or even a relevant, sustained wave function. Quantum models must then resort to mind/brain inferaction and mind/ brain dualism, utilizing the hypothetical quantum theory of the observer. How can the observer be in the brain if the observer is the brain? The only recourse then is to a sub-quantum foundation of reality and mental process, in the quantum vacuum. The vacuum is everywhere, at the most fundamental level of reality, and is the only known source of physical reality. It is proposed that the vacuum is the physical correlate of Whitehead's mental or spiritual world. The vacuum is a single, interconnected medium, in keeping with our assertion that the Mind is fundamentally One. The link between observation and actuality in quantum theory gives us a single Universe, honed out of the enormous realm of possibility that obtain for the evolution of the Universe, life, and consciousness through the agency of a single God in interaction with a single Universe.

We have need for the hypothesis of God, as a unitying principle, as the source of order, and as the final causality that make science work. Process in nature goes from the physical to the mental pole, and consciousness is only achieved in higher order entities. For God, process starts at the uppermost place on the mental pole, 
as a consciousness that is higher than our own, everywhere present. Whitehead introduced God into his metaphysics because, fundamentally, he needed God to complete it. Thus the main section on God is at the end of Process and Reality. In the same sense, if God is active, and not just a passive observer, science will need God for its completion.

\section{Reference}

A. Abbrevioled References:

1. MT: Whitehead, Allred North. Modes of Thought. New York: The Free Press, 1968.

2. PR: Whitehead, Alfred North. Process and Reality: Corrected Edition. Ed. David R. Griffin and Donald W. Sherburne. New York: The Free Press, 1978.

3. RM: Whitehead, Alfred North. Religion in the Making: Lowell Lectures 1926. New York: Macmillan, 1927.

B. Other References:

1. Attar, Farid Un-Din. The Conference of the Birds. Nott, C. S., and Garcin de Tassy, Trans. London: Roulledge and Kegan Paul, 1961.

2. Bohm, David, and Basil J. Hiley. The Undivided Universe: An Ontological Interpretation of Quonlum Theory. London: Routledge, 1993.

3. Brookes, Daniel R., and E.O. Wiley. Evolution as Entropy: Toward a Unified Theory of Biology. Chicago: University of Chicago Press, 1986.

4. Brown, Jason W. "Foundations of Self." Psychoscience, <http://www.psychoscience.net/ loundationsbrown.htm> (2008).

5. Buss, David M. et al. "Adaptations, Exaptations, and Spandrels." American Psychologis! 53(1998): 533-548.

6. Chew, Geoffrey P. "A Historical Reality that includes Big Bang, Free Will, and Elementary Particles." Physics and Whiteheod: Quanlum Process, and Experience. Ed. Timothy E. Eastman and Hank Keeton. Albany, New York: State University of New York Press, 2004. 84.91.

7. Edinger, Edword F. Ego and Archetype: Individuation ond the Religious Funclion of the Psyche. Boston: Shambala, 1992.

8. Germine, Mark. "Virtual Brain States and Non-locality of the ERP." Medical Hypotheses 62 (2004): 629.634.

9. Goddard, Dwight, Ed. A Buddhist Bible. Boston: Beacon Press, 1970.

10. Kauffman, Stuant A. Investigations. Oxford: Oxford University Press, 2000.

11. Kauffman, Stuart A. "Towards a Post Reductionist Science: The Open Universe." Physics Archives. ArXiv: 0907.2492 [physics.hist-ph] 15 Jul 2009.

12. Kauffman, Stuart A. The Origins of Order: Self-Organization and Seleclion in Evolution. New York: Oxford University Press, 1993. 
13. Kimura, Motoo. "Evolutionary Rate of the Molecular Level." Nature 217 (1968): 634-626.

14. Laszlo, Ervin. Science and the Akashic Field: An Integral Theory of Everylhing. Rochester, Vermont: Inner Traditions, 2004.

15. Morris, Simon. "On the First Day, God Said..." Americon Scientist 91:4 (2003).

16. Neumann, Erich. The Origins and History of Consciousness. Princelon: Princeton University Press, 1954.

17. Requardi, Manfred. "Wormhole Spaces: The Common Couse for the Black Hole EntropyArea Law, the Holographic Principle and Quantum Entonglement." Physics Archives arXiv: $0910.4017 \mathrm{v})(2009)$.

18. Roy, Sisir. Planck Scale Physics, Pregeometry and the Nolion of Time. <hitp:/l unw.chronos.msu.ru/EREPORTS/roy> (2009).

19. Schweber, Silvan S. QED and the Men that Made It: Dyson, Feynmon, Schwinger, and Tomonago. Princeton: Princeton University Press, 1994.

20. Stopp, Henry P. Mindful Universe: Quantum Mechonics and the Parlicipaling Observer. Berlin: Springer-Verlag, 2007.

21. Susskind, Leonard. The Block Hole Wars: My Baille with Stephen Hawking to Make the World Safe for Quantum Mechanics. New York: Little, Brown and Company, 2008.

22. Susskind, leonard. The Cosmic Landscape: String Theory and the Illusion of Intelligent Design. New York: Little, Brown and Company, 2006.

23. Swami, Shree Purohit, and William B. Yeats, Trans. The Ten Principle Upansishads. London: Faber and Fober, 1970.

24. 't Hoofi, Gerard. "Does God Play Dice?" Physics World 18:12 (2005). 